\title{
Singularidades Químico-Farmacêuticas da Ficção Queirosiana
}

\author{
João Manuel Costa ${ }^{1}$, João Paulo André2* \\ ${ }^{1}$ Escola Secundária de Santa Comba Dão \\ 2 Departamento/Centro de Química, Universidade do Minho, Braga \\ jandre@quimica.uminho.pt
}

\begin{abstract}
A obra ficcional de Eça de Queirós é rica em detalhes descritivos que se estendem ao domínio das Ciências Naturais. A Química, quer pela via farmacêutica quer pela das banais aplicações domésticas, não escapou à pena realista do autor, contribuindo de forma marcante para a composição do retrato que este nos quis deixar da sociedade portuguesa de finais de Oitocentos: a partir da sua obra ficcional é possível elaborar um rol de cerca de quatro dezenas de compostos, produtos e preparações químicas e farmacêuticas.

Nesta perspectiva, e a título de exemplo, a causa da morte de Juliana - a criada de Luísa n’ O Primo Basílio e uma das personagens mais fascinantes, e hediondas, da obra de Eça - é-nos apresentada através de uma narrativa de teor científico, constituindo um caso paradigmático na literatura realista universal. Este e outros casos queirosianos são analisados ao longo deste artigo que, por limitações de espaço, foi divido em duas partes.

Na primeira, que agora se publica, apresentam-se as secções “Águas minerais e antiácidos” e "Metais pesados”. Na segunda, apresentar-se-ão as secções "Fármacos e preparações de origem vegetal”, "Óleos, solventes e produtos resinosos" e "Outros fármacos e produtos químicos".
\end{abstract}

Há cem anos que eu canto esta canção Sem cabeça porém com o coração. Porque o País do Eça de Queiroz Ainda é... o País de todos nós!..

José Carlos Ary dos Santos, As Palavras das Cantigas.

\section{INTRODUÇÃO}

A Europa pós-iluminista empenhou-se na afirmação da função e do estatuto da Ciência e do impacto desta na sociedade, o que, a partir da terceira década do século XIX, viria a ser reforçado por uma concepção positivista do mundo (Auguste Comte, Herbert Spencer,...) [1]. Neste ambiente favorável ao desenvolvimento científico, a Química terá sido o domínio das Ciências Naturais que mais progressos alcançou ao longo do século.

A Química Analítica, conquistando a sua consolidação definitiva, tornava possível a interpretação das relações de massa das reacções químicas, necessária para o avanço e implantação da teoria atómica. A introdução do espectroscópio em 1859, por Bunsen e Kirchhoff, e a realização do Congresso de Karlsruhe em 1860 - que ao estabelecer, em definitivo, a diferença conceptual entre átomo e molécula, permitia que todos os químicos pudessem falar uma mesma e inequívoca linguagem - foram acontecimentos de maior relevância e impacto. Posteriormente, em 1869, ao dispor sistematicamente os elementos químicos de acordo com as suas propriedades físicas e atómicas, Mendeleev criava a mais importante base de racionalização da Química moderna, a Tabela Periódica.

Na Química Orgânica, em particular no período entre 1860 e 1900, verificaram-se enormes progressos no desenvolvi- mento de métodos de síntese, com destaque para os de derivados do fenol (este, por sua vez, obtido do alcatrão da queima da hulha). A Química dos produtos naturais, sobretudo a dos açúcares, teve igualmente um progresso notável.

Na Química-Física, da mesma forma, assistiu-se a um período de grande evolução: a teoria cinética dos gases conduziria à distribuição de Maxwell-Boltzmann das velocidades moleculares e, na termodinâmica, é introduzido em 1865 o conceito de entropia. Entretanto, o estudo da dinâmica das reacções levaria à queda do antigo conceito de afinidade química e à aplicação dos princípios de equilíbrio aos sistemas químicos. Por sua vez, Arrhenius, no seguimento de estudos de electroquímica, propôs em 1884 o revolucionário conceito de ião.

De forma algo simbólica, o século que findava assistia em 1900 à apresentação da lei de Max Planck que descreve a radiação electromagnética emitida por um corpo negro, abrindo o caminho para a teoria quântica [2]. No mesmo ano morria em Paris Eça de Queirós.

José Maria de Eça de Queirós (Figuras 1 e 2) - um dos principais responsáveis pela introdução das estéticas do Realismo e do Naturalismo em Portugal, de acordo com o conteúdo programático apresentado em 1871, de forma explícita, na $4{ }^{a}$ Conferência do Casino ("A Literatura Nova ou o Realismo como Nova Expressão da Arte”) e, de forma implícita, através de muitas das suas obras recorreu assídua e consistentemente à Química nos seus contos e romances, o que, como se verá, não constituiu um mero exercício de exotismo narrativo ou de snobismo erudito. 


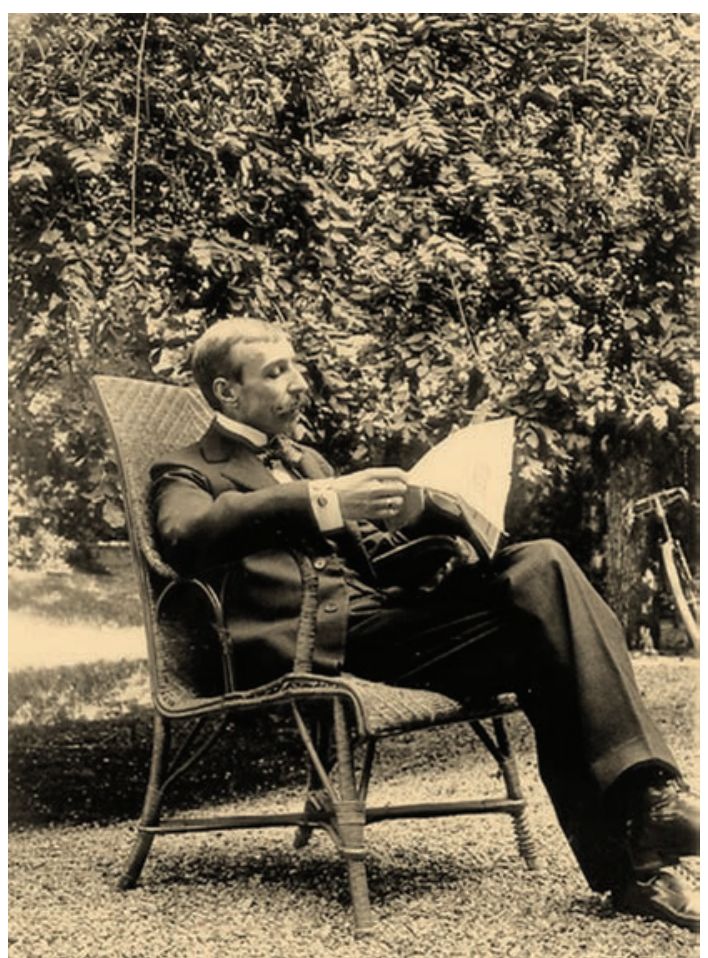

Figura 1 - José Maria de Eça de Queirós (1845-1900)

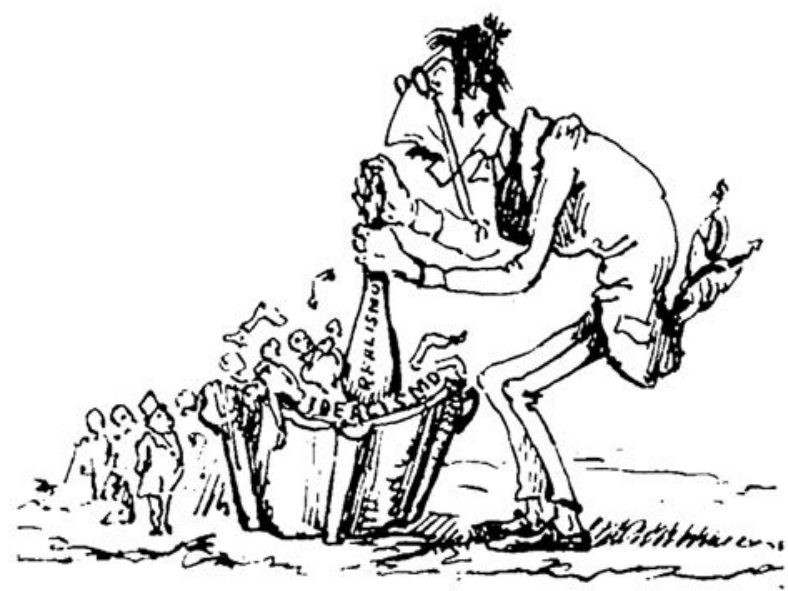

Figura 2 - Caricatura de Eça de Queirós da autoria de Rafael Bordalo Pinheiro por altura das Conferências do Casino

\section{A Química EM EÇA}

São dois, fundamentalmente, os planos em que a Química e as temáticas afins aparecem na obra de Eça de Queirós: o doméstico e o farmacêutico. No primeiro a Química contribui para a autenticidade das descrições de ambientes e de lides caseiras ("O reverendo sacerdote, ele próprio, passajava as suas meias, cosia as suas voltas e limpava a batina com benzina; vivia arrumando, espanejando o quarto, e todos os dias polia o seu candeeiro de latão, com uma dissolução de ácido oxálico que ele mesmo ia comprar à Farmácia Azevedo.” - O Conde d'Abranhos); no segundo, o universo da Química tanto pode constituir um ingrediente necessário para a verosimilhança da efabulação (por exemplo a digitalis que Juliana tomava para o coração, n’ O Primo Basílio), como configurar-se fisicamente em cenário, tal como acontece n’ A Capital, em que uma farmácia é um dos vários espaços em que se move o protagonista, Artur Corvelo.

Com efeito, n’ A Capital podemos encontrar as descrições ecianas que mais directamente nos transportam ao mundo da farmácia galénica: “À custa de muito álcool canforado...”; "quando pisava linhaça no almofariz da farmácia”; “com o casaco de laboratório que pertencera ao hábil Alfredo, preparava resignadamente, sob o olhar paternal do Vasco, a sua primeira garrafada de mistura salina.”. Vasco, o farmacêutico, augura a Artur uma carreira promissora: "Demais a mais, não seria difícil, em alguns meses, com os estudos que ele tinha, iniciá-lo na manipulação dos elementos químicos «que é de tanta responsabilidade, minhas boas senhoras...»"; "se o Sr. Corvelo gostava de empregar os seus vagares, como era justo na sua idade, por que não unia o útil ao agradável? Por que não estudava a bela Física, e a bela Química, que lhe seriam de tanto auxílio no seu futuro farmacêutico?”. Esta ideia, contudo, não agradava a Artur: "Praticante de farmácia! Parecia parvo, de pena na mão e os cabelos esguedelhados, rolando assim dos céus poéticos onde pairava até aos almofarizes da botica do Vasco!”; "Pertencer ao Vasco, pisar num almofariz semente de linhaça, perpetuamente? Não!”; “E que emprego, pisar linhaça, e fazer misturas salinas...”.

A respeito das referências farmacêuticas na obra romanesca de Eça, teremos de ter em consideração que na época os produtos farmacêuticos eram, regra geral, de formulação bastante simples e raramente possuíam designações comerciais. Assim, aos leitores de Eça, tornava-se bastante fácil reconhecer e identificar os compostos e preparados mencionados na sua obra (o nitrato de prata, o xarope de codeína, o bismuto,...). Recorde-se que, num arremedo trocista do Realismo e do Naturalismo, Camilo Castelo Branco elegeu igualmente o mundo da farmácia para pano de fundo de Eusébio Macário (1879).

A Química na ficção queirosiana não se esgota, todavia, nos dois planos assinalados, ocorrendo ainda num terceiro: o metafórico. Este permitiu a Eça aspergir a sua ácida e corrosiva ironia sobre a sociedade. Exemplos disso são a benzina para a "nódoa” do governo (O Conde d' Abranhos), ou o bicarbonato para as indigestões provocadas pela poesia de Alencar (Os Maias).

N’Os Maias encontramos um notável exercício de ironia no episódio em que, em casa dos Gouvarinhos, se discute a educação escolar das crianças e no qual uma "dama de preto" se queixa dos examinadores: "Era um escândalo as exigências, as dificuldades que punham, só para poder deitar $R R$... Ao pequeno dela tinham feito perguntas estúpidas, as mais reles; assim, por exemplo, o que era o sabão, porque lavava o sabão?...”; acrescentando que "Não havia verdadeiramente senão uma coisa digna de se estudar, eram as línguas. Parecia insensato que se torturasse uma criança com botânica, astronomia, física... Para quê? Coisas inúteis na sociedade. Assim, o pequeno dela, agora, tinha lições de Química... Que absurdo! Era o que o pai dizia - para quê, se ele o não queria para boticário?”. 
Nos “preparatórios”, efectuados no Porto entre 1858 e 1861, a par das Latinidades e de outras disciplinas clássicas, Eça teve de estudar Química. Esta disciplina haveria mais tarde de revelar-se-lhe útil, tanto na prosa ficcional que criaria como no primeiro emprego que obteve, em 1867, n’ O Distrito de Évora, um jornal da oposição. Neste jornal foi autor único dos múltiplos textos publicados, assinando uma diversidade de rubricas e de secções, normalmente sob nomes fictícios. Para o efeito recorria a fontes variadas de informação estrangeira que ele próprio traduzia [3].

O tema da Exposição Universal de Paris de 1867 teve direito a várias páginas do jornal e no $\mathrm{n}^{\circ} 44$, de 9 de Junho, a propósito de um método de clarificação de águas potáveis (um assunto dilecto, como se verá), Eça dava aos seus leitores uma verdadeira lição de Química ao descrever o sistema patente no expositor de um tal Sr. Birt de Birmingham: "Para obter uma excelente água de mesa, basta preparar uma dissolução neutra de trissulfato de alumina e juntar esta dissolução à água que se quer purificar, na proporção de uma parte por sete mil, ou uma colher de sopa em um balde de dimensão ordinária. Apenas isto é feito, aparece uma nuvem no líquido e descem os frocos rapidamente para o fundo, arrastando todas as matérias orgânicas e desembaraçando a água de toda a cor, de todo o sabor desagradável, e de todo o cheiro. Em seis ou sete horas acha-se completo o depósito; e isto, quer para mil litros, quer para um só. O princípio desta purificação é o seguinte: toda a água contém bicarbonato de cal dissolvido em proporção mais ou menos forte. O ácido sulfúrico do trissulfato de alumina apodera-se da cal, para formar um sulfato quase insolúvel, que se precipita. O hidrato de alumina, estando liberto, forma com a matéria orgânica um produto que se precipita também. O ácido carbónico do bicarbonato de cal fica livre e comunica à água um sabor agradável.” [4]. Trata-se, como é fácil de concluir, da precipitação de hidróxido de alumínio a partir do sulfato de alumínio e do ião bicarbonato, método ainda hoje utilizado para a clarificação de águas potáveis.

Quanto ao contributo da Química para a riqueza descritiva dos ambientes e actividades domésticas, o conto Civilização constitui um exemplo paradigmático. Assim, no n. 202 dos Campos Elísios, a casa parisiense de Jacinto, "As travessas (de prata) subiam da cozinha e da copa por dois ascensores, um para as iguarias quentes, forrado de tubos onde a água fervia; outro mais lento, para as iguarias frias, forrado de zinco, amónia e sal, e ambos escondidos por flores tão densas e viçosas que era como se até a sopa saísse fumegando dos românticos jardins de Armida.”.

São várias as explicações possíveis para o sistema de arrefecimento do ascensor das iguarias frias de Jacinto, mas é também plausível que Eça, numa preocupação desmesurada pelo rigor técnico-científico, tenha fornecido informação relativa a dois métodos distintos de refrigeração. Senão vejamos: no século XIX, “amónia” tanto poderia significar o amoníaco como uma solução aquosa deste gás, ou mesmo um sal de amónio. Com efeito, o amonía- co constitui um bom agente refrigerante sendo, por isso, ainda hoje usado em sistemas de frio industrial.

O francês Ferdinand Carré foi pioneiro neste domínio, ao criar e patentear em 1859 um sistema de refrigeração baseado neste gás. O público pôde admirá-lo na Exposição Universal de Londres de 1862 (Figura 3), onde, para fascínio geral, uma máquina produzia $200 \mathrm{~kg}$ de gelo por hora [5]. Seria esta grande novidade da época o engenho de refrigeração do elevador de iguarias frias da casa parisiense de Jacinto? Ou seria, tão somente, um sistema de arrefecimento baseado num sal de amónio? (Há vários séculos que o nitrato de amónio era conhecido como um sal criostático, dado a sua dissolução em água - endotérmica - provocar arrefecimento).

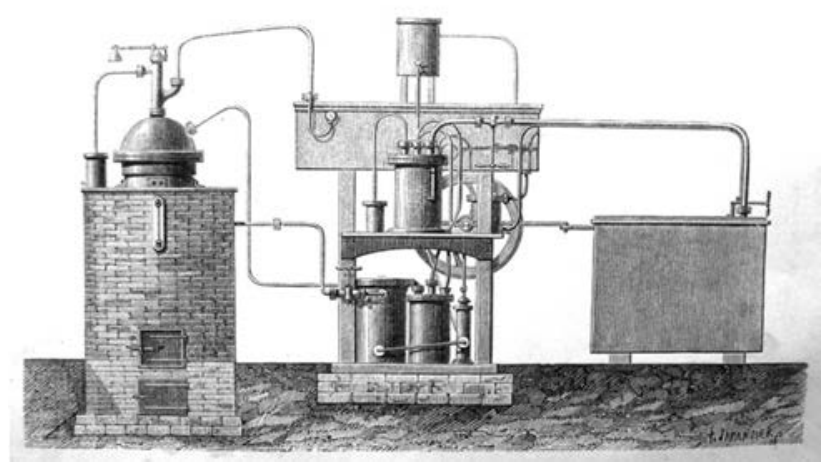

Figura 3 - Engenho de Ferdinand Carré para a produção de gelo (ilustração do livro L'Eau de Gaston Tissandier, Paris, 1869)

O amoníaco, porém, é referido n’ A Capital para descrever um ambiente de odor desagradável: "Da escada do Espanhol, sombria, saía um cheiro enjoativo de amoníaco.”.

Na presente análise não se fez o levantamento das inumeráveis referências aos metais constituintes dos objectos (travessas de prata, tinteiros de latão, grades de ferro,...) contudo são dignas de registo as alusões a alguns outros materiais.

Assim, n’ A Capital pode ler-se: “o livro parecia passar sobre a cidade como uma gota de água sobre guta-percha”. A imagem da água sobre gutta-percha também aparece na carta de Eça enviada de Newcastle a Teófilo Braga, datada de 12 de Abril de 1878, a propósito da escrita d' O Primo Basílio. A gutta-percha é igualmente referida n’ A Cidade $e$ as Serras: "Encostado e como refugiado no meu braço, este Jacinto novo começou a lamentar que as ruas, na nossa Civilização, não fossem calçadas de guta-percha! E a guta-percha claramente representava, para o meu amigo, a substância discreta que amortece o choque e a rudeza das coisas! Oh maravilha! Jacinto querendo borracha, a borracha isoladora, entre a sua sensibilidade e as funções da Cidade!”.

A gutta-percha é um tipo de borracha, proveniente do látex da Palaquium gutta; foi muito utilizada na segunda metade do século XIX, em particular no revestimento de cabos subaquáticos de telégrafo (Figura 4) e em ornamentação de mobiliário e no fabrico de peças decorativas. O uso deste 
material declinou desde que, em 1907, o químico americano de origem belga Leo Baekeland, a partir do fenol e do formaldeído sintetizou a baquelite, uma resina sintética polifenólica considerada um pioneiro do plástico [6]. É pois bizarro que n’ A Tragédia da Rua das Flores (romance que terá sido escrito em 1877-1878, mas publicado só em 1980) se possa ler a seguinte passagem: “...sobre uma mesa redonda, coberta por um feio pano felpudo, de cores azulinas, estava um buvard de pele de serpente de Klem, com um brasão a prata; folhas de papel, marcado por Wyon; uma faca de baquelite; ...”. Estamos, com efeito, perante mais uma evidência - esta de teor científico - a atestar a intervenção espúria no manuscrito original de Eça.

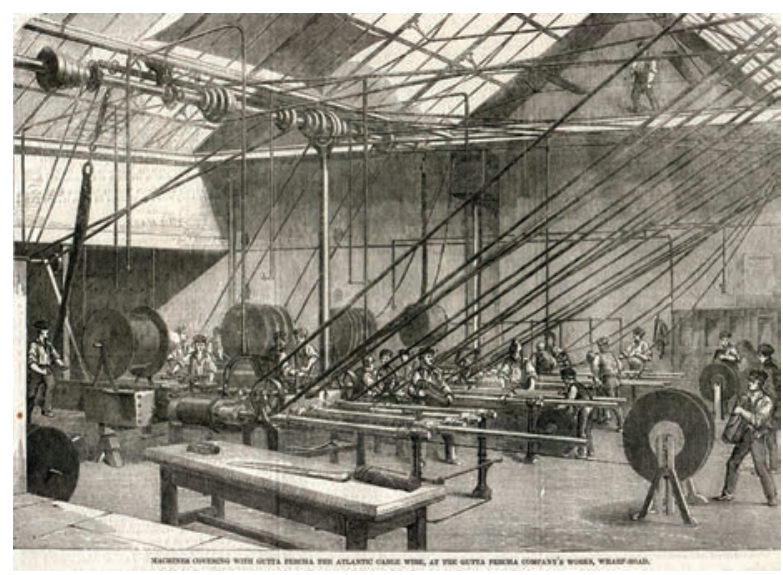

Figura 4 - Revestimento dos cabos submarinos de telégrafo com gutta-percha

\section{1 ÁGUAS MINERAIS E ANTIÁCIDOS}

Na obra de Eça há um lugar de honra para a grande mesa; recorde-se a este propósito o jantar no Hotel Central (Figura 5) que, n’ Os Maias, João da Ega oferece em honra de Cohen, ou o que, n' A Capital, Artur oferta aos "amigos" no Hotel Universal e pelo qual haveria de pagar com "lágrimas de raiva” "vinte e duas libras!”.

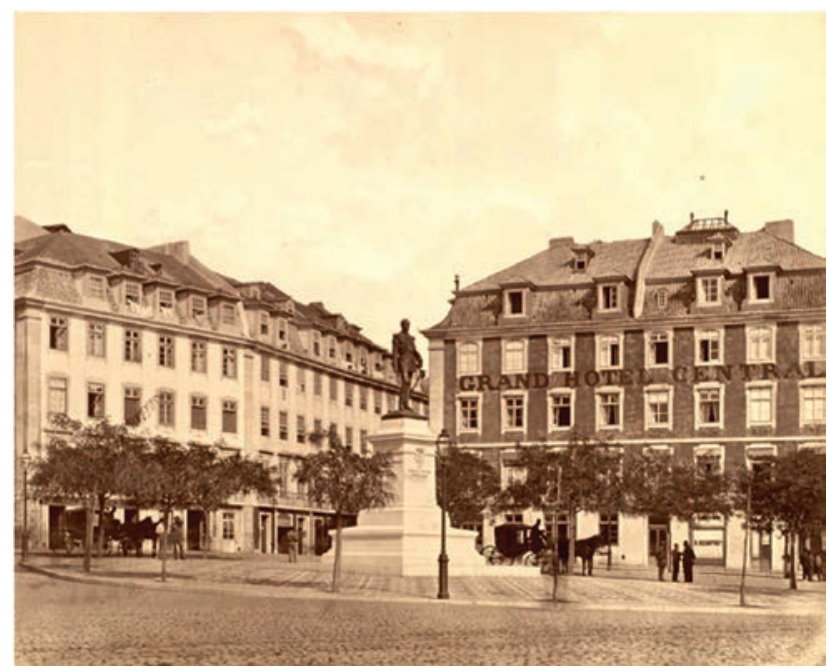

Figura 5 - Hotel Central (Praça Duque da Terceira, Lisboa) em 1877

Como inevitável corolário, Eça apresenta-nos igualmente um infindável sortido de auxiliares digestivos e antiácidos.
As águas, em particular as minerais, assumem na escrita queirosiana um estatuto de quase obsessão: “E de águas havia sempre no Jasmineiro um luxo redundante - águas geladas, águas carbonatadas, águas esterilizadas, águas gasosas, águas de sais, águas minerais, outras ainda, em garrafas sérias, com tratos terapêuticos impressos no rótulo" (Civilização); “Todo um aparador porém vergava sob o luxo redundante, quase assustador de águas - águas oxigenadas, águas carbonatadas, águas fosfatadas, águas esterilizadas, águas de sais, outras ainda, em garrafas bojudas, com tratados terapêuticos impressos em rótulos"; "Ó Jacinto! E as águas carbonatadas? E as fosfatadas? E as esterilizadas? E as sódicas?”; “começava por se encharcar com um imenso copo de água oxigenada, ou carbonatada, ou gasosa, misturada dum conhaque raro, muito caro”, ou ainda "Água de Evian... Não, de Bussang! Bem, de Evian e de Bussang!” (A Cidade e as Serras).

Em relação a estas duas águas, a primeira é bem conhecida na actualidade e a segunda, também francesa, é proveniente da região dos Vosges com o mesmo nome; trata-se de uma água ferruginosa, adequada ao tratamento de anemias. Também n’ A Capital nos aparecem as referências às águas minerais: "Tornou-se então muito afável com Artur; ofereceu-lhe da sua água Apollinaris para misturar com o vinho”. A água Apollinaris é uma água mineral gasosa de Bad Neuenahr, na Alemanha, que, de acordo com a tradição, é adequada para a cura de ressacas (!).

Não podemos ignorar que a época de Eça coincidiu com o desenvolvimento da hidroterapia, a qual colocou na moda a cura de várias doenças pela via das águas termais, de acordo com a especificidade da composição química destas. Este interesse terapêutico pelas águas surgiu de forma natural, no seguimento do grande nível de desenvolvimento que a Química Analítica entretanto tinha atingido. A este respeito, como referem Leonardo et al, "a partir de meados do século XIX começaram a ser definidos os principais parâmetros físicos, químicos e biológicos para avaliar a potabilidade da água e prever os seus efeitos fisiológicos, que interessam para a sua adopção como agente terapêutico" [7]. ${ }^{1}$

\footnotetext{
1 Ao longo da segunda metade do séc. XIX foram vários os químicos e médicos que efectuaram análises de águas minerais nacionais [7]. Neste contexto destacam-se os contributos de dois notáveis químicos portugueses: Agostinho Vicente Lourenço (1826-1893) que, entre outros estudos, se dedicou à análise de águas minerais de numerosas termas e que publicou, em francês, um livro sobre águas termais portuguesas [http://www.spq.pt/docs/Biografias/AVLourencoport.pdf] e António Ferreira da Silva (1853-1923) que, a par de outros interesses científicos, se devotou à investigação das águas de Portugal. Entre outros trabalhos, legou-nos As águas do rio Sousa e os mananciais e fontes da cidade do Porto (1881) e As águas minero-medicinais das Caldas da Saúde (Santo Tirso) (1889) [http://sigarra.up.pt/up/pt/web_base.gera_ pagina?P_pagina=1010975]; foi o fundador e director do Laboratório Químico Municipal da cidade do Porto e da Sociedade Portuguesa de Química.

A nível literário, é forçoso mencionar a obra Banhos de Caldas e Águas Minerais (1875) de Ramalho Ortigão - companheiro de Eça na escrita d' O Mistério da Estrada de Sintra - que constitui um roteiro pelas várias estações termais e uma descrição das diferentes águas medicinais portuguesas, o que é precedido por várias considerações acerca dos tratamentos termais.
} 
A vida de Eça foi marcada por várias crises gastrointestinais. Em 1897, quase no fim da vida, a conselho do seu médico português em Paris, Dr. Melo Viana, Eça procurou melhoras na estância termal francesa de Plombières (Figura 6), na região dos Vosges, famosa pelas suas águas radioactivas, sulfatadas e sódicas [8]. É interessante constatar que Eça se deslocou a estas termas no ano seguinte ao da descoberta das radiações urânicas por Henri Becquerel (as quais Marie Curie, com a colaboração do marido Pierre, em 1898, designou por radioactividade [9]). Embora a causa exacta da morte de Eça - três anos depois da estadia em Plombières - seja desconhecida, os sintomas relatados nas cartas escritas à esposa e aos amigos, sugerem uma amebíase. Outros acreditam poder ter sido um tumor maligno no pâncreas $[10,11]$.

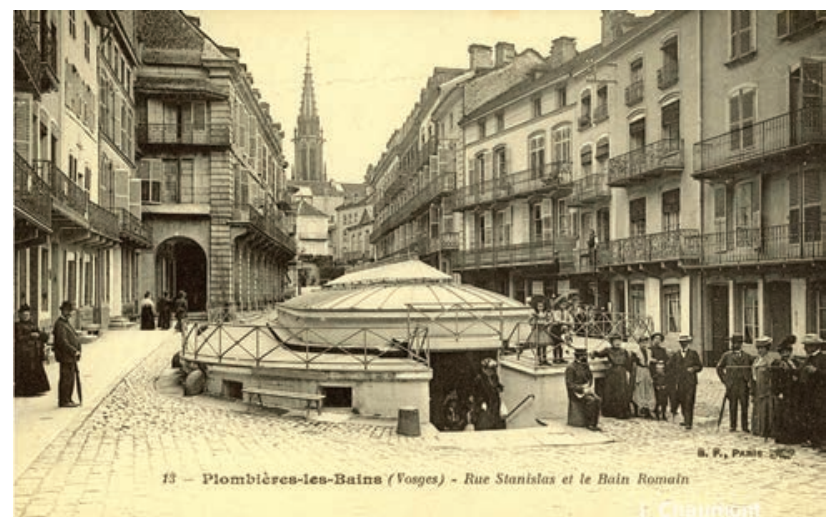

Figura 6 - Rua Stanislas e entrada para os banhos romanos em Plombières em finais do séc. XIX

Ao longo da sua obra, Eça exalta com frequência as virtudes das águas nacionais, em particular a de Vidago que, tendo alcançado estatuto medicinal, era adquirida, de forma engarrafada (Figura 7), nas farmácias. A água de Vidago aparece citada n’ A Relíquia: “um cavalheiro, de colete de veludo negro, veio ocupar o talher fronteiro, junto de uma garrafa de água de Vidago, de uma caixa de pílulas e de um número da Nação” e “O Senhor Lino ofereceu-me da sua água de Vidago - e conversamos das terras da Escritura”, e igualmente n’ A Ilustre Casa de Ramires: “Dizias então do estômago... Sim, filha, combalido. E há dias mais pesado, desde o tal cabrito no espeto e da companhia beberrona do Manuel Duarte. Tu tens cá água de Vidago?... Então, Barrolinho, sê angélico. Manda trazer já uma garrafinha bem fresca”. Aparece ainda n’ A Tragédia da Rua das Flores, quando o brasileiro Prudêncio, vizinho de quarto de Marinho no Hotel Universal, se lamenta de padecimento hepático e Victor lhe aconselha Vidago.

As águas minerais gasosas são ricas em bicarbonato, actuando assim como antiácido ao neutralizarem o excesso de ácido clorídrico gástrico. A mesma função desempenham os sais de fruto e o bicarbonato (os primeiros são compostos essencialmente por bicarbonato e carbonato de sódio - “ de soda”, em Eça). Um dos produtos da reacção de neutralização do ácido é o gás dióxido de carbono. Seria este o responsável pelos alívios gástricos de D. Felicidade de Noronha d’ O Primo Basílio? - “Aquelas agitações abalavam a digestão comprimida de D. Felicidade; felizmente, como ela dizia, arrotava! Graças a Deus, louvada seja Nossa Senhora, que podia arrotar!”.

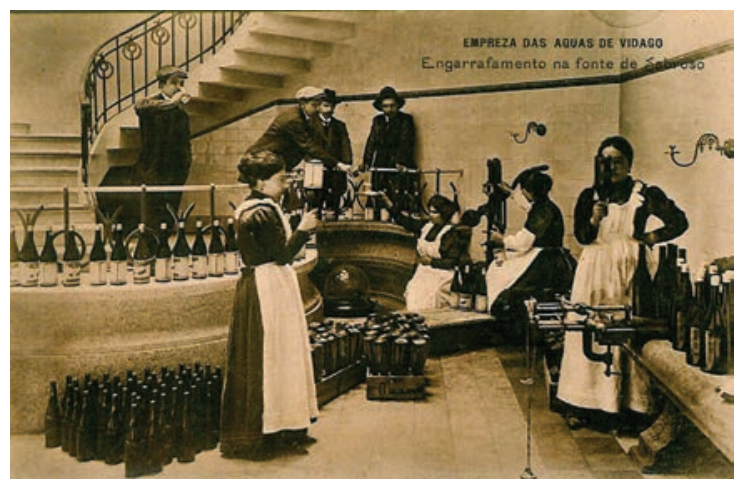

Figura 7 - Engarrafamento da água Vidago em finais do século XIX

A Ilustre Casa de Ramires é uma obra pródiga em referências a neutralizadores da acidez gástrica, incluindo o bicarbonato de sódio e os sais de fruto (Figura 8): "E enquanto [Gonçalo, o Fidalgo da Torre] se despia, depois de beber aos goles um copo de água com bicarbonato de soda, já martelava a primeira linha do conto, à maneira lapidária da "Salambô”; “Oh Bento, ouve lá! Tu não encontraste na mala que eu trouxe de Lisboa, ou no caixote, um frasco de vidro com um pó branco? É um remédio inglês que me deu o Sr. Dr. Matos... Tem um rótulo em inglês, com um nome inglês, não sei que, fruit salt... Quer dizer sal de frutas...”; "Recordou então o famoso fruit salt que lhe recomendara o Dr. Matos, - arrebatou o frasco, correu à sala de jantar, em camisa. E, a arquejar, deitou duas fartas colheradas num copo de água da Bica-Velha, que esvaziou de um trago, na fervura picante. - Ah! que consolo, que rico consolo!...”; e prossegue: "É que passei uma noite horrenda, Bento! Pesadelos, pavores, bulhas, esqueletos... Foram os malditos ovos com chouriço; e o pepino... Sobretudo o pepino! Uma ideia daquele animal do Titó... Depois, de madrugada, tomei o tal fruit salt, e estou óptimo, homem!”.

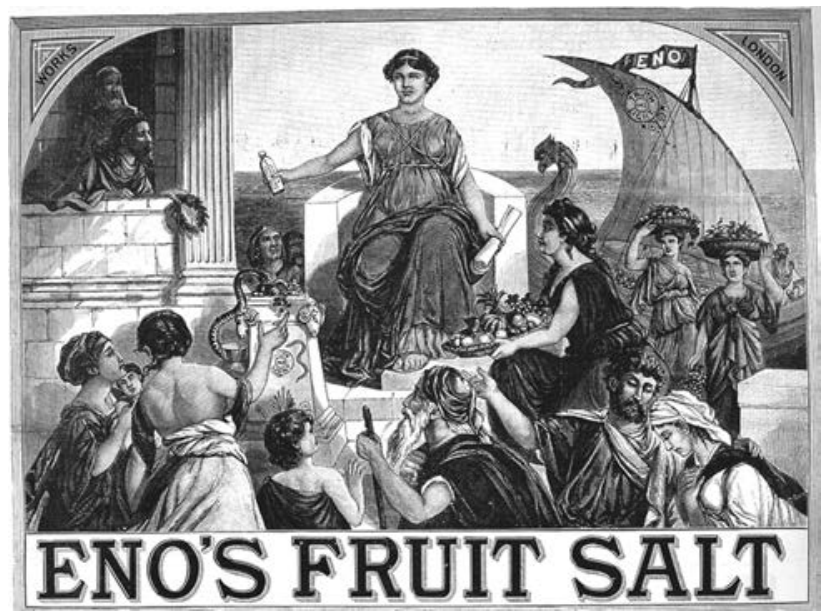

Figura 8 - Anúncio inglês aos sais de fruto (1885)

Ainda no que respeita a águas, encontramos n’ $O$ Primo Basílio referência à “água sulfúrica”, recomendada por Sebastião ao "seu primo afastado" que se encontrava constipado: “Aconselhou-lhe água sulfúrica com leite fervido.”; "E não te esqueças: água sulfúrica da Farmácia Azevedo 
na Rua de São Roque”. Apesar da designação utilizada por Eça para estas águas, pode encontrar-se numa tese de doutoramento apresentada à Escola Médico-Cirúrgica do Porto em 1900, sob o título “As Aguas Sulfurosas nas Doenças Chronicas do Nariz, Pharynge e Larynge”, que a água sulfurosa, rica em sulfureto e hidrogenossulfureto, era usada numa variedade de aplicações terapêuticas, que incluía o tratamento da coriza (inflamação da mucosa nasal que pode ser acompanhada de espirros, secreção e obstrução nasal) [12]. Poderá, assim, estar esclarecido o conselho de Sebastião ao primo.

A “magnésia de James” (Figura 9) é outro antiácido encontrado na obra de Eça, cidadão cosmopolita atento às novidades da época. N' O Crime do Padre Amaro, o Carlos da farmácia dá uma peculiar lição sobre sofrimentos vários, a qual remata aconselhando "Que use a magnésia de James!”. N’ A Tragédia da Rua das Flores, Dâmaso, perante o descrédito de Genoveva pelos médicos portugueses, não mais se atreveu a sugerir-lhe qualquer remédio, e "Um dia mesmo que ia a falar de magnésia, corou, tossiu e empregou um circunlóquio”.

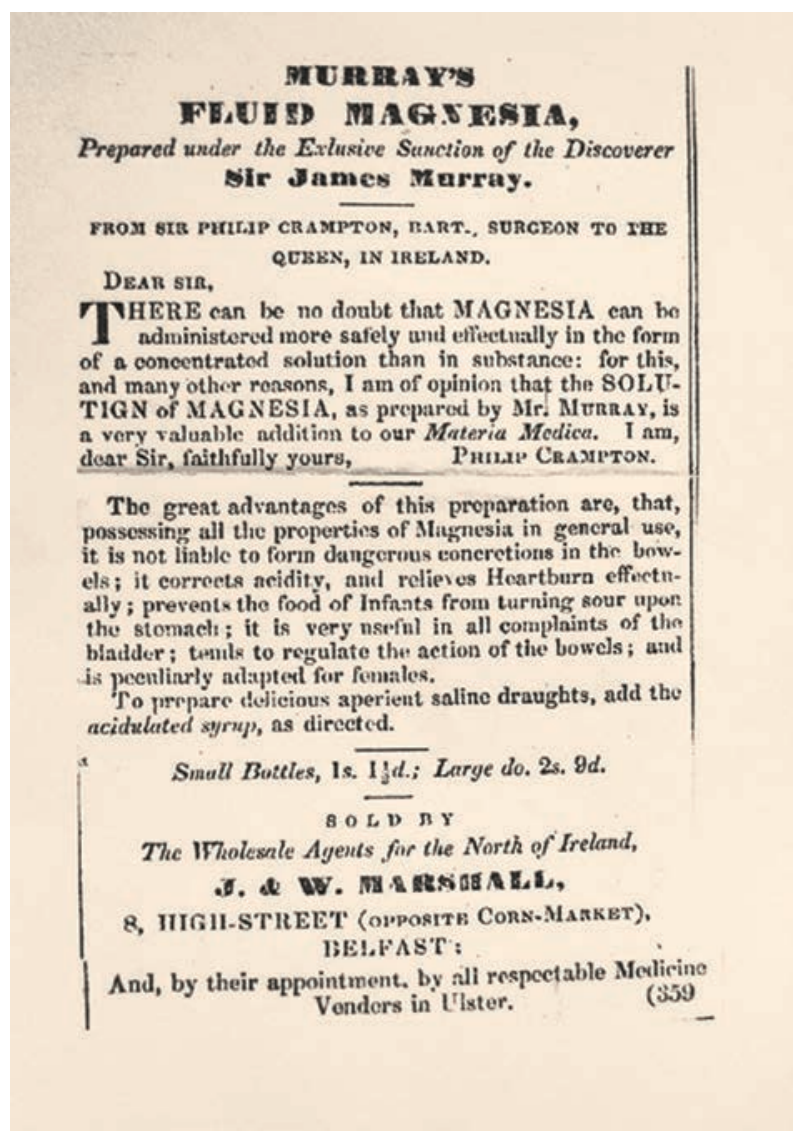

Figura 9 - Anúncio inglês do séc. XIX à "Magnésia de James”

A “magnésia de James” refere-se ao leite de magnésia (também conhecida como magnésia), uma suspensão de hidróxido de magnésio em água a que ainda hoje se recorre como antiácido e como laxante. Foi Sir James Murray, médico e farmacêutico britânico que, em 1829, preconizou a sua aplicação a mal-estares gástricos, tendo esta, no entanto, só sido patenteada em 1873, altura a partir da qual passou a ser vendida em diversos países $[13,14]$. A magné- sia constituía assim uma modernidade quando, em 1875, $O$ Crime do Padre Amaro foi publicado.

Outro clássico reparador das fragilidades gástricas é o bismuto que, em Eça, aparece n’ A Relíquia nos relatos das aventuras do Raposão pela Terra Santa: "Depois, recordando os meus dissabores intestinais em Jericó, por muito amar os divinos e pérfidos melões da Síria - perguntei ao amável físico se nessas ocorrências ele preconizava o bismuto...”.

Eça estava familiarizado com este elemento, como bem deixou expresso na carta de 30 de Agosto de 1884 ao Visconde de Pindela e ao Conde de Arnoso: "Ficalho partiu - e eu passei a estar doente. Há três dias que os meus pobres intestinos se sublevaram e estou-lhes caindo em cima (e dentro) com a severa repressão do bismuto" (Correspondência). Pela mesma altura escrevia também a Oliveira Martins: “A minha sublevação intestinal tem resistido à repressão conservadora do bismuto” (Correspondência).

O bismuto é um metal pesado relativamente pouco tóxico e há mais de duzentos anos que os seus compostos são utilizados para uma variedade de aplicações terapêuticas. Devido à actividade antimicrobiana do $\mathrm{Bi}(\mathrm{III})$ para com a Helicobacter pylori, este elemento é actualmente ainda usado, sob diversas formulações, para o tratamento de úlceras pépticas. Os compostos mais habituais são o subsalicilato de bismuto (Pepto-Bismol), o subcitrato de bismuto coloidal ( $\mathrm{De}-\mathrm{Nol})$ e o ranitidina-citrato de bismuto (Pylorid). Os complexos de citrato de Bi(III) baseiam-se na unidade dimérica [(cit)BiBi(cit) $]^{2-}$ que, por associação com outras unidades, à custa de novas ligações como, por exemplo, ligações de hidrogénio, formam estruturas em cadeia e em folha, as quais se depositam sobre a superfície das úlceras. O Bi(III) liga-se rapidamente a grupos tiol de moléculas como o tripéptido glutationa (GSH) formando o tiolato $\left[\mathrm{Bi}(\mathrm{SG})_{3}\right.$ ] que, apesar da sua elevada estabilidade termodinâmica ( $\log K=29,6)$, é muito lábil, permitindo uma rápida permuta do $\mathrm{Bi}(\mathrm{III})$ entre grupos tiol livres. A bactéria $H$. pylori consegue sobreviver sob condições de elevada acidez no estômago porque utiliza uma enzima, a urease, que produz amónia, neutralizando o ácido do meio. A actividade antibacteriana do Bi(III) deverá residir na capacidade que os tiolatos de $\mathrm{Bi}(\mathrm{III})$ têm para inibir a urease [15].

\subsection{Metals pesados}

Para além do bismuto, já referido, aparecem ainda em Eça os altamente tóxicos mercúrio, arsénio e antimónio. Apesar da toxicidade do mercúrio, os médicos gregos da Antiguidade recorreram a unguentos deste metal e, no séc. XVI, Paracelso recomendou os seus compostos para o tratamento da sífilis; prática que se prolongaria até à primeira década do século Xx [16, 17]. A partir de 1910 ficou disponível no mercado um medicamento conhecido por Salvarsan, resultante do trabalho de investigação do alemão Paul Erlich (Prémio Nobel da Medicina em 1908), ao qual ainda acrescentaria em 1912 o Neosalvarsan. Tratava-se de dois compostos or- 
ganometálicos de arsénio, sendo o segundo mais hidrossolúvel e de menor toxicidade. Apesar da acção bactericida destes compostos sobre o agente causador da doença, a Treponema pallidum, só a partir de 1941, com a disponibilização pública da penicilina, seria possível combater de forma eficaz esta infecção. A identificação da Treponema pallidum, por Fritz Schaudinn e Erich Hoffmann, em 1905, e o desenvolvimento, no ano seguinte, de um teste de detecção da infecção, por August Paul von Wassermann, constituíram os primeiros grandes passos contra a ameaça que a sífilis constituía para a procriação, a família e o bem-estar social. Os resultados dos testes disponíveis na época revelaram números verdadeiramente alarmantes: em média, 10 a $15 \%$ da população das grandes metrópoles europeias estava infectada com a Treponema pallidum [18].

Neste contexto médico-social, não serão de estranhar as várias referências de Eça ao mercúrio como agente terapêutico. N' O Crime do Padre Amaro, este aparece no excerto: "Foi então que o Carlos, recordando-se, leu a receita que amarrotara na mão. A indignação emudeceu-o - vendo que era aquele todo o resultado da sua grande entrevista com a autoridade! - Que é? perguntou sofregamente a Amparo. O que era? e no seu furor, desdenhando o segredo profissional e o bom renome da autoridade, o Carlos exclamou: - É um frasco de xarope de Gibert para o senhor administrador! Aí tem a receita, Sr. Augusto. Amparo, que, com alguma prática de farmácia, conhecia os benefícios do mercúrio, fez-se tão escarlate como as fitas flamejantes que lhe enfeitavam a cuia.”. Ainda n' O Crime do Padre Amaro, do Sr. Gouveia Ledesma, secretário-geral em Leiria, ficamos a saber que "em Lisboa arruinara um pequeno património com o amor de Lolas e de Carmens, ceias no Mata, muita caça no Xafredo e perniciosas convivências literárias: aos trinta anos estava pobre, saturado de mercúrio e autor de vinte folhetins românticos na Civilização”.

N’ A Capital encontramos também uma alusão ao xarope de Gibert, esta com fins irónicos: "Sabe o que lhe aconselho que faça ao seu drama? - Como tratamento interno, xarope de Gibert; como tratamento externo, cautério de nitrato de prata.”.

A composição do xarope de Gibert, usado para o tratamento da sífilis, pode ser encontrada numa tese de doutoramento apresentada à Escola Médico-Cirúrgica do Porto em 1896, intitulada “O Tratamento do Shyphilitico”: 0,20 cg de biiodeto de mercúrio, 10 g de iodeto de potássio e 500 g de xarope simples [19].

O mercúrio é tóxico tanto na forma elementar - especialmente os seus vapores - como nas formas inorgânica (iões mercúrico, $\mathrm{Hg}^{2+}$, e mercuroso, $\mathrm{Hg}_{2}{ }^{2+}$ ) e organometálica. Uma vez absorvido pelo organismo, este metal é oxidado pela catalase a $\mathrm{Hg}^{2+}$, que se liga a proteínas plasmáticas que o distribuem por todos os órgãos. Igualmente, o mercúrio inorgânico, na forma de $\mathrm{Hg}^{2+}$, liga-se nos rins a moléculas endógenas com grupos tiol (-SH), tais como as metalotioneínas, sendo de seguida captado por células epiteliais dos túbulos proximais e da alça de Henle, e pelos glomérulos. Nas células acumula-se nos lisossomas, mitocôndrias e membranas. A sua retenção nos lisossomas e o seu longo tempo de permanência nos rins e cérebro explicam a sua neurotoxicidade [20].

O arsénio é um semimetal tóxico que aparece na obra de Eça sob a designação de arsénico, nome popular dado ao trióxido de arsénio, $\mathrm{As}_{2} \mathrm{O}_{3}$. N' $\mathrm{O}$ Mistério da Estrada de Sintra, uma história repleta de venenos, podemos ler: "Ora - disse-lhe eu -, uma coisa me admira em tudo isto. - Qual? - É que não tivesse deixado sinais o arsénico...-Foi ópio interrompeu ele, com uma simplicidade infantil" e "O que admira é que não deixasse vestígios o arsénico! - Mas foi o ópio! - responde M. C.” e, ainda, “Atenta no que fazes, temerário! Abre teus olhos, inconsiderado mortal! Essa perdiz, cujo peito insidioso e pérfido está lourejando a teus olhos; foi apimentada com arsénico. Aquele Chambertin, que te espera como uma onda da lagoa Estígia, emboscada por detrás daquele letreiro envernizado, aparentemente simples, elegante, convidativo, mas em verdade tenebroso e fatal como o dístico do festim de Baltasar, aquele vinho, que te oferece um beijo refalsado e fementido, está destemperado com ácido prússico. As trufas, lúbricas, venais, devassas, envoltas nesses fígados de pato, estão empapadas nos temperos letais da cozinha dos Bórgias!”.

A referência aos Bórgias é interessante por ser, no imaginário popular, sinónimo de ambição e impiedade. O famoso e infame veneno dos Bórgias, sabe-se hoje, era o trióxido de arsénio - pó branco com aparência de açúcar, inodoro e praticamente insípido e solúvel em água e no vinho. Ao longo dos séculos, sob o pretexto de se destinar a matar ratos, foi utilizado para fins menos lícitos e, em França, chegou a ser conhecido como "pó da sucessão” [21].

A elevada toxicidade deste semimetal do grupo 15, que possui os estados de oxidação As(III) e As(V), advém essencialmente da grande afinidade do As(III) para biomoléculas com grupos tiol. São conhecidos vários mecanismos bioquímicos responsáveis pela toxicidade de elementos como o arsénio, o mercúrio e outros metais e semimetais. Assim, em princípio, qualquer composto destes elementos tóxicos poderá afectar componentes e/ou processos celulares vitais por formação de radicais livres, peroxidação lipídica, alteração da homeostasia do cálcio, inibição da reparação do ADN, indução de apoptose, activação do factor de transcrição nuclear kappa B e metilação do ADN [22].

N' O Egipto - Notas de Viagem, Eça realça que, a par das especiarias e de todo o tipo de produtos perfumados, o antimónio podia ser encontrado no bazar das drogas do Cairo. Este semimetal do grupo 15 - precedido pelo arsénio e também tóxico [23] - foi no passado usado na Medicina e na cosmética. Assim, o tartarato duplo de antimónio(III) e potássio foi usado como emético e o sulfureto de antimónio(III) para a pintura dos olhos. Na Idade Média tornou-se popular o uso da "pílula eterna” para combater a prisão de ventre. Esta "pílula” consistia numa esfera de antimónio metálico que era engolida sendo o seu efeito produzido pela irritação das paredes intestinais; de seguida era recolhida, lavada e guardada para situações futuras - e passada às gerações seguintes [24]. 


\section{AgradeCIMENTOS}

Os autores agradecem as frutuosas discussões com o Professor Jorge Calado, a gentil cedência de material bibliográfico por parte do Engenheiro Luís Ferro, a cuidada leitura crítica das colegas Ana Paula Esteves e Cláudia Cunha Pascoal, bem como as enriquecedoras sugestões dos revisores do manuscrito.

\section{REFERÊNCIAS}

[1] M.H. Santana, "Literatura e Ciência na Ficção do Século XIX - A Narrativa Naturalista e Pós-Naturalista Portuguesa”, Imprensa Nacional Casa da Moeda, Lisboa, 2007

[2] A.J. Ihde, "The Development of Modern Chemistry", Harper \& Row, Nova Iorque, 1964

[3] M.F. Mónica, “Eça de Queirós”, Quetzal, Lisboa, 2009

[4] E. de Queiroz, "Páginas de Jornalismo - O Distrito de Évora (1867)”, 2. ${ }^{\circ}$ vol., Lello, Porto, 1981

[5] E. Granryd, B. Palm, "Refrigerating Engineering”, Stockholm Royal Institute of Technology, Estocolmo, 2005

[6] P. Le Couteur, J. Burreson, “Napoleon’s Buttons“, Tarcher-Penguin, Nova Iorque, 2003

[7] A.J.F. Leonardo, D.R. Martins, C. Fiolhais, Química Nova 34 (2011) 1094-1105

[8] “Doenças", in A. Campos Matos (coord.), "Dicionário de Eça de Queiroz”, Caminho, Lisboa, 1993

[9] J.P. André, A. de Sá, Química (Boletim da SPQ) 31 (2011) 120-137
[10] “Morte”, in A. Campos Matos (coord.), "Dicionário de Eça de Queiroz”, Caminho, Lisboa, 1993

[11] A. Sequeira, Medicina Interna 7 (2000) 188-196

[12] A.H. Teles, "As Aguas Sulfurosas nas Doenças Chronicas do Nariz, Pharynge e Larynge”, Escola Médico-Cirúrgica do Porto, Porto, 1900

[13] The Sydney Morning Herald, 7 de Outubro, 1846 (disponível em http://trove.nla.gov.au/ndp/del/page/1516118, acedido em 30.5.2013)

[14] http://www.ulsterhistory.co.uk/jamesmurray.htm (acedido em 30.5.2013)

[15] I. Bertini, H.B. Gray, E.I. Stiefel, J.S. Valentine (eds), "Biological Inorganic Chemistry: Structure and Reactivity”, University Science Book, Sausalito, 2007

[16] E.R. Caley, J. Chem. Educ. 5 (1928) 419-425

[17] V. Kumar, B. Tate, J. Chem. Educ. 59 (1982) 971-972

[18] L. Hutcheon, M. Hutcheon, “Opera: Desire, Disease, Death”, University of Nebraska Press, Lincoln, 1996

[19] J.J. de Moura, "O Tratamento do Syphilitico - Dissertação Inaugural apresentada á Escola Medico-Cirurgica do Porto”, Porto, 1896

[20] L. Bensefa-Colas, P. Andujar, A. Descatha, La Revue de Médecine Interne 32 (2011) 416-424

[21] J.P. André, Química (Boletim da SPQ) 125 (2012) 55-59

[22] J. Gailer, J. Inorg. Biochem. 108 (2012) 128-132

[23] T. Gebel, Chemico-Biological Interactions 107 (1997) 131144

[24] J. Emsley, “The Elements of Murder - A History of Poison”, Oxford University Press, Nova Iorque, 2005

\section{Actualidades Científicas}

\section{Nanotubos de Carbono: é VÊ-LOS a CRescer}

Um grupo de investigadores da Universidade Tsinghua, em Pequim, conseguiu fazer crescer um nanotubo de carbono com mais de meio metro de comprimento, cerca do dobro do tamanho do que já haviam conseguido.

A equipa mostrou que a distribuição de Schulz-Flory (uma função matemática que descreve as proporções relativas de polímeros de comprimentos diferentes após um processo de polimerização, com base nas suas probabilidades relativas de ocorrência) pode ser aplicada para descrever as proporções relativas de nanotubos de carbono de comprimentos diferentes, com base na actividade do catalisador/probabilidade de desactivação. O grupo recorreu à deposição química em fase de vapor para fazer crescer, ao longo de duas horas, um longo nanotubo de carbono sobre um substrato de sílica. Após a optimização das condições de processamento, conseguiram obter um nanotubo de carbono com $550 \mathrm{~mm}$ de comprimento.

Os autores deste estudo consideram que estão lançadas as bases para a adopção de um plano racional para a produção controlada de nanotubos/nanofios. Qual será a próxima meta? Um metro?

(adaptado de “Nanotubes grow to record lengths”, http://www.rsc.org/chemistryworld/2013/07/carbon-nanotube-record-half-metre-long e R. Zhang, Y. Zhang, Q. Zhang, H. Xie, W. Qian, F. Wei, ACS Nano 7 (2013) 6156)

Paulo Mendes

(pjgm@uevora.pt)

Faça-se sócio da SPQ, receba o Boletim QUÍMICA e tenha acesso:

Às últimas notícias do mundo da Química - A artigos de relevo sobre a Química - A entrevistas com membros ilustres da Química - A uma agenda dos mais importantes eventos sobre Química aqui e além fronteiras. 